\title{
EVALUATION OF MINERALIZED PLASMATIC MATRIX GRAFT AFTER SURGICAL REMOVAL OF IMPACTED MANDIBULAR THIRD MOLARS (RANDOMIZED CLINICAL STUDY)
}

\author{
Abdelmageed H. Al-Fakhrany*, Mohammad A. Shuman** and Bahaa-Eldin A. Tawfik*
}

\begin{abstract}
The purpose of the study was to evaluate mineralized plasmatic matrix (MPM) as a graft material in reducing the complications associated with the surgical extraction of impacted mandibular third molar. Patients \& Methods: The study was conducted on selected 26 patients. Their ages ranged from 19 to 38 years old with mean (SD) of 28.0 (6.67). The patients were selected and divided randomly into two groups (13 patients each). All the patients were subjected to surgical removal of impacted mandibular third molar by the same surgical team and using the same surgical protocol for both groups. After surgical extraction, the sockets in the first (study) group filled with mineralized Plasmatic matrix (MPM), while in the second (control) group, the socket closed without any graft. The patients were evaluated pre and post surgery at $1^{\text {st }}, 3^{\text {rd }}, 5^{\text {th }}, 7^{\text {th }} \& 15$ days to evaluate pain, trismus, facial swelling and thermal sensitivity of lower second molar. Bone density was evaluated immediately and at 1, 3 and 6 months postoperatively. The results showed; that the pain, trismus, and facial swelling in addition to thermal sensitivity were higher in the control group when compared with the MPM group, with statistically significant differences in some evaluation periods. Bone density was higher in MPM group than in control group with high significant difference $(\mathrm{P}<0.01)$. The conclusion: of this study showed that MPM application after surgical removal of impacted mandibular third molar was more effective as a graft material for reducing the surgical complications through the whole postoperative period.
\end{abstract}

\section{INTRODUCTION}

Extraction of impacted mandibular third molar is a common procedure in dental practice and may be accompanied with intraoperative and postoperative complications such as excessive pain, trismus, swelling and thermal sensitivity. $(1,2)$ These complications may be due to excessive bone removals, which lead to root exposure of the neighboring second molar, which may last in some patients for long time or lead to second molar extraction $^{(3,4)}$.

These complications include damage of soft and hard tissues around the tooth, or even mandibular fracture; they occur during and after surgery and depend on the tooth position in the bone. ${ }^{(5)}$ Alveolar bone resorption, is almost occur after extraction, leading to decrease in ridge volume and alteration of ridge contour. Attention should be given for bone healing following third molar extraction, as it is associated with periodontal defects on the distal surface of an adjacent second molar ${ }^{(6,7)}$.

Several biocompatible graft materials have been used to control these complications, which include allografts, alloplasts grafting materials and membrane. These materials were used for alveolar ridge preservation and may prevent aforementioned post extraction complication ${ }^{(8)}$. Platelet rich plasma (PRP) show a good graft material with a large efficacy ${ }^{(9)}$. Several techniques have been utilized to collect concentrated platelet and concentrated growth factors(CGF). Compared to PRP and platelet rich growth factors (PRGF), platelet rich fibrin (PRF) and CGF have many advantages over PRP.

\footnotetext{
*Ass. Prof, Oral and Maxillofacial Surgery Faculty of Dental Medicine, Boys, Cairo Al-Azhar University

**Ass. Prof, Oral and Maxillofacial Surgery Faculty of Dental Medicine, Bossiest, Al-Azhar University
} 
First, PRF can be squeezed to form a membrane and can be used as fibrin bandage serving as a matrix to accelerate the healing of wound edges. Second, PRF does not use bovine thrombin or other exogenous activators in the preparation process. Its natural fibrin architecture seems responsible for a slow release of growth factors and matrix glycoproteins during 7 days. Third, the chairside preparation of PRF is quite easy and fast and simplifies processing without any artificial biochemical modification, Fourth, this produces an inexpensive autologous fibrin membrane in few minutes and eliminates the cost of membrane ${ }^{(10-13)}$.

The use of concentrated platelet in combination with graft materials is recently recommended. Platelet contains high quantities of growth factors, such as transforming growth factors $B 1$ (TGF- $\beta 1$ ) and 32 (TGF- 32 ), fibroblast growth factor (FGF), platelet-derived growth factor (PDGF) and, epithelial growth factor (EGF). In addition, insulin growth factor-I (IFG-I), which enhance the healing process and vascular endothelial growth factors (VEGF), which stimulates cell proliferation and regulates up angiogenesis ${ }^{(14,15)}$. Plasmatic matrix is a new way which might facilitate the use of bone grafts. The Mineralized Plasmatic Matrix (MPM) developed by Dr. Persse ${ }^{(16)}$ and modified by Dr. EL Moher ${ }^{(17)}$. It is an autologous blood product highly concentrated in platelets conjucted with fibrin in a liquid or jell state combined with a bone substitute. The fibrin can become bound to bone particles, the filling material is easy to shape. Also, a PRF-type membrane can be generated ${ }^{(18)}$. This may lead to better bone repair and regeneration ${ }^{(19)}$. Platelets also play a role in host defense mechanisms at the wound site, which attract macrophage cells. Platelet concentrates may contain small amounts of leukocytes that synthesize interleukins involved in the non-specific immune reaction. Antimicrobial activity of platelet concentrates against several bacterial species involved in oral infections has also been reported ${ }^{(20)}$.
MPM graft can be an effective procedure for socket preservation due to its numerous advantages. It may serve as a third-generation platelet concentrate with potential applications in various fields (21) These materials can become bound to bone particles and the filling material is easy to shape and applied into the extraction socket ${ }^{(22)}$. Therefore, this study aimed to evaluate mineralized plasmatic matrix (MPM) as a graft material in reducing the risk of complications after surgical extraction of impacted mandibular third molar.

\section{PATIENTS AND METHODS}

This randomized controlled clinical study was conducted on 26 patients (13 male and 13 female) between 2014 and 2017. The patients had horizontal impacted mandibular third molars indicated for surgical extractions, in the right and left side of the mandible. The patients were divided randomly into two equal (Study and control) groups, 13 patients each. Their age ranged from (19 to 38 ) old years, with the mean of $28 \pm 6.67$ in the study group and $29.5 \pm 6.37$ in the control group. All the patients were subjected to surgical removal of impacted mandibular third molar by the same surgical team and using the same surgical protocol for both groups. In the first (Study) group, the defects of extracted teeth were filled with mineralized plasmatic matrix (MPM), while in the second (control) group, the socket closed without any graft, (Tab.1).

TAB. (1) Showing; Patients sex, site of implant and age in both groups.

\begin{tabular}{|l|l|c|l|}
\hline & & Study group & $\begin{array}{l}\text { Control } \\
\text { group }\end{array}$ \\
\hline Patient gender & $\begin{array}{l}\text { Male, no (\%) } \\
\text { Female, no (\%) }\end{array}$ & $\begin{array}{l}7(53.85) \\
6(46.15)\end{array}$ & $\begin{array}{c}6(46.15) \\
7(53.85)\end{array}$ \\
\hline Affected side & $\begin{array}{l}\text { Left mandible } 3^{\text {rd }} \\
\text { molar, no (\%) } \\
\begin{array}{l}\text { Right mandible } \\
\text { molar, no (\%) }\end{array}\end{array}$ & $8(61.54)$ & $6(46.15)$ \\
\hline $\begin{array}{l}\text { Age in years, mean } \\
\text { (Standard deviation) }\end{array}$ & $28.0(6.67)$ & $\begin{array}{c}29.5 \\
(6.37)\end{array}$ \\
\hline
\end{tabular}


The exclusion criteria were; teeth with acute infection, patients with uncontrolled systemic diseases that affect bone healing, irradiation to the head or neck region within 12 months of surgery and pregnancy. The patient selected were almost similar in the difficulties of surgical conditions, such as; teeth location in the jaw, depth of impaction, ramus relationship, and osteotomy. According to Pell \& Gregory ${ }^{(23)}$ classification, a horizontal and mesioangular position, class II, level $\mathrm{B}$ with a moderate difficulty of surgical extraction was selected in this study, the patients were free from any systemic disease that may affect bone healing, (Fig. 1).

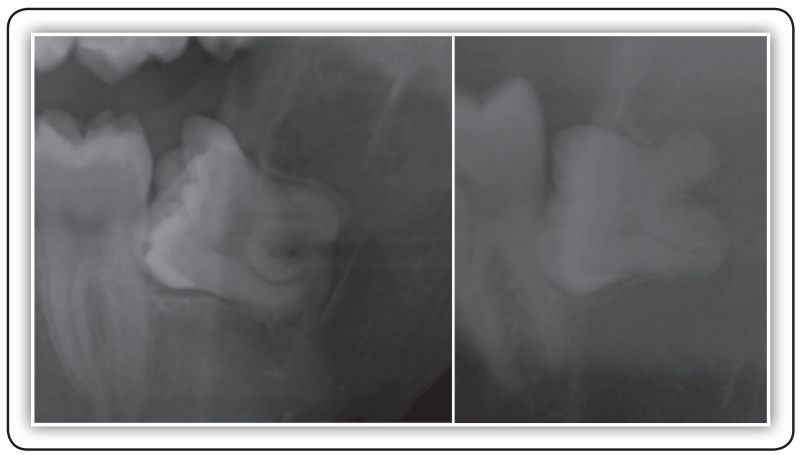

Fig.(1) Showing nearly similar horizontal impactions in both groups.

A Complete history including; name, age, sex, occupation, residence, chief complaint, medical and dental history was taken from all patients. Intraoral examination was done to determine the condition of oral and pericoronal tissue of the impacted third molar.

Panoramic views and a digital standardized periapical $\mathrm{x}$-rays films with parallel cone were performed for all patients to evaluate and classify the impacted third molars and the amount of the bone around it.

All patients were signed an informed consent about the procedure, the postoperative recovery time, possible complications that might occur.

\section{Operative procedure}

The surgical procedure and bone removal was identical in both groups, the mucosa was incised and a recommended mucoperiosteal flap was reflected. Bone removal around the lower third molar was accomplished. The interlocked tooth structure resistance was removed by a fissure surgical bur, No 703, mounted on high speed handpiece which splitting from buccal surface to lingual surface. A suitable elevator was used to luxate the impacted third molar and finally removed by suitable forceps. After tooth extraction and toilet of the sockets, mineralized plasmatic matrix was used to fill the surgical site of the first group only, while in the second group, the wound was closed without graft.

\section{Preparation of mineralized plasmatic matrix}

Patient's blood were taken and applied in 3 tubes of $5 \mathrm{~mL}$ without anticoagulant. The venous blood was placed into the centrifugation machine to separate the red blood cells from the platelets for $15 \mathrm{~min}$ at $2700 \mathrm{rpm}$. The result obtained after the centrifugation was two layers: a yellow plasma liquid on the top of the tube separated from the red blood cells in its bottom ${ }^{(24)}$._The yellow part was taken and added to a cup that contains Synthetic bone and the whole preparation was mixed for few seconds and the MPM was obtained in the form of gel and placed into the socket (Fig. 2).

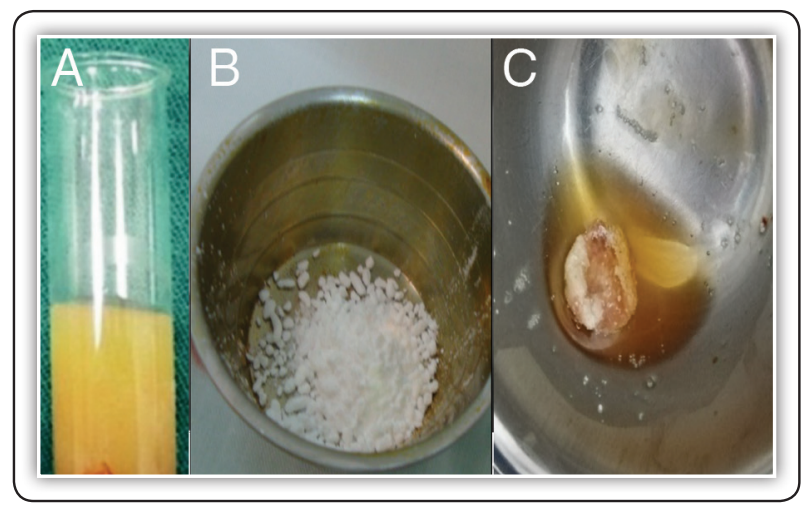

Fig.(2) Showing; MPM preparation via separation of plasma from venous blood (A), synthetic bone (B) and plasma mixing with synthetic bone graft to form $\operatorname{MPM}(\mathrm{C})$. 


\section{Postoperative management}

All patients have had Amoxicillin-Clavulanic, $1 \mathrm{gm}$ just pre-operatively, and twice daily postoperatively for 5 days to decrease the possibility of post-operative infection. Paracetamol $1000 \mathrm{mg}$ was prescribed for the relief of pain if necessary and recorded. Cold application was applied at the site of surgery for six hours post-operatively and mouths rinsing with chlorohexidine mouth wash starting on the second post-operative day for 5 days. The sutures were removed at seventh post-operative day.

\section{Post-operative assessment and evaluation}

\section{Post-operative pain:}

Preoperatively, the patients were pain free. Pain was evaluated at first, third and fifth days postoperatively through the visual analogue scale (VAS) recorded from 0 to 10 . Where (0) represented the absence of pain, (1) was lowest pain and score of (10) was maximal pain ${ }^{(25,26)}$.

\section{Post-operative swelling:}

Swelling was assessed, while the patient sitting in an upright position. The data was collected at first, third, fifth, seventh and fifteen days postoperatively and compared with preoperative measures. This achieved using a 2-0 silk wire to measure the distance between the angle of lower jaw $(\mathrm{G})$ and each of 4 facial reference points: tragus (T), outer canthus of the eye (C), sub nasal point (S), and pogonion $(\mathrm{P})$. Those points were marked with a demographic pen (Fig. 3). The mean taken and subtracted from pre-operative measure. Swelling was characterized as mild (1-3 mm), moderate (4-6 $\mathrm{mm})$ and severe $(7-10 \mathrm{~mm})^{(27)}$.

\section{Post-operative trismus:}

Trismus was evaluated postoperatively at first, third, fifth, seventh and fifteen days. This through measuring the maximum mouth opening using a digital caliper applied between incisal edge of the upper and lower central incisors and compared to pre-operative measure ${ }^{(27)}$.

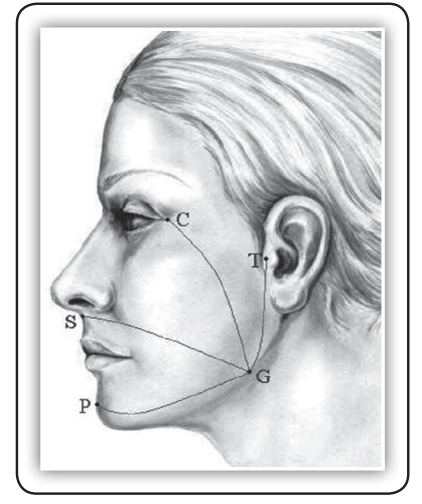

Fig.(3) Showing facial swelling reference points.

\section{Thermal sensitivity}

Thermal Sensitivity of $2^{\text {nd }}$ molar was assessed and recorded Pre.O \& P.O. in both groups, In VAS from $0-10$, where 0 was no sensitivity, while 1 is lowest and 10 was highest sensitivity.

\section{Bone Density}

Intraoral periapical radiograph were taken and digitalized using standardized techniques advocated by (Peretz\&Goes) ${ }^{(28)}$. Measurement of bone density at alveolar bone crest \& middle of the socket at Region of interest (ROI) was recorded immediately $\&$ at 1,3 and 6 months post operatively ${ }^{(29)}$.

\section{Statistical Analysis}

Results were expressed as group means and their standard deviations. Ordinal scores of pain and thermal sensitivity (rank data; scores 0 to 10) were compared between the two groups using the non-parametric Mann-Whitney test at each day of evaluation. Continuous data were analyzed with a repeated measures analysis of variance. The analysis model included the effects of intervention (study group vs. control group), stage of evaluation, patient's sex and extraction site (right mandible vs. left mandible) as a well as patient's age as a covariate. Non-significant two-way interactions were removed from the final model. Tukey-Kramer test was used to compare differences between means. All analyses were performed using the 
statistical analysis system, SAS Version 9.10 (SAS Institute Inc., Cary, NC, USA), and a probability value $<0.05$ was considered statistically significant.

\section{RESULTS}

A total of 26 patients indicated for mandibular third molar extraction were included in this study. The number and mean value of age, sex of patients, in addition to the site of extraction in each group, were shown in (Tab,1). The results in both groups at whole periods of this study was not affected by the different age, sex or site of extraction. Statistically, there was no significant differences $(\mathrm{P}>0.05)$.

The mean time necessary for flap elevation, bone removal, and tooth extraction was $43.695 \pm 4.52$ minutes in the first (Study group) and 40.85 \pm 3.07 in the second (Control group), without any significant effect on the results $(\mathrm{P}>0.05)$.

\section{Postoperative (P.O.) Pain:}

Preoperatively, patients were all pain free. The pain on first, third and fifth days post-operatively was recorded according to visual analogue scale (VAS) and the two groups were compared with each other. Patients in the study group (MPM) had significantly less pain than those in the control group at all time of evaluations. Pain was most intense on the $1^{\text {st }}$ and $3^{\text {rd }}$ postoperative day. At both times, the pain score medians (ranges) was 4 (4) in the study group, compared to score 5(4) at $1^{\text {st }}$ P.O. day and $5(3)$ at $3^{\text {rd }}$ P.O.day in the control group. The level of pain felt by the patients were higher in the control group when compared with the MPM, however, the statistical comparison showed no statistical significant differences between the 2 groups (Table 2 ). Furthermore, the number of analgesic doses taken in the test group was significantly lower when compared with the control group. The pain score at $5^{\text {th }}$ and $7^{\text {th }}$ P.O. day was 3(2) and score of 1(3) in the study group in comparing to score of 4 (3) and score $3(4)$ in the control group respectively. The significant difference of pain score were observed between the two groups at 5 and 7 days, postoperatively, where $(\mathrm{P}<0.05$ and $\mathrm{P}<0.01)$ respectively. However, there is no any pain at 15 P.O. day in both group. (Tab.2)

TAB. (2) Showing; Post-operative pain score in the study and control group at the times of evaluations with (VAS).

\begin{tabular}{|c|l|l|}
\hline Day & Study group & Control group \\
\hline 1 & $4(4)$ & $5(4)$ \\
3 & $4(4)$ & $5(3)$ \\
5 & $3(2)^{*}$ & $4(3)$ \\
7 & $1(3)^{* *}$ & $3(4)$ \\
15 & $0(0)$ & $0(0)$ \\
\hline
\end{tabular}

Values are medians (ranges).

Pain scores: 0 to 10 (refer to the methods section for explanation).

Groups within a day differ significantly $(* P<0.05$; $* * P<0.01)$ based on the non-parametric Mann Whitney test at each time point.

\section{Postoperative trismus:}

Maximum mouth opening was recorded preoperatively in study and control groups and compared with $1^{\text {st }}, 3^{\text {rd }}, 5^{\text {th }}, 7^{\text {th }} \& 15$ days postoperatively. Preoperatively, the mouth opening ranged from 4.2 to $4.9 \mathrm{~cm}$ in the study group with the mean (SD) of $38.42 \pm 10.23$; while in control group, it ranged from 4.3 to 4.9 and the mean (SD) was $40.95 \pm 4.29$. Trismus was evaluated as the degree of mouth opening after tooth extraction. The interincisal distance was significantly reduced for both groups after surgery. There was an improvement in the mouth opening in study and control groups from 1 st to $7^{\text {th }}$ postoperative day, with reduction in mouth opening in the control than study group without statistical significant differences between them (Tab.3).

At first postoperative day, the mean of mouth opening in study group was $35.83 \pm 2.69$, while the mean in the control group was $33.64 \pm 2.20$. 
Statistically there was significant difference between two groups where $(\mathrm{P}<0.001)$. At $3^{\text {rd }}, 5^{\text {th }}$, $7^{\text {th }}$ and 15 days, the mean value of mouth opening were; $33.75 \pm 2.40,35.96 \pm 2.38,37.66 \pm 1.75$ and $44.38 \pm 1.60$ in the study group compared to $33.64 \pm 2.20,31.31 \pm 1.98,32.76 \pm 1.59,34.67 \pm 1.49$ and $44.12 \pm 1.7$ in the control group respectively. Statistically there was no significant difference between the two groups, where $(\mathrm{P}>0.05)$.

TAB. (3) Showing; Pre-and post-operative maximum mouth opening $(\mathrm{mm})$ in the study and control group.

\begin{tabular}{|ll|l|l|}
\hline Day & & Study group & Control group \\
\hline Preoperative & & $38.42 \pm 10.23$ & $40.95 \pm 4.29$ \\
\hline Postoperative & 1 & $35.83 \pm 2.69$ & $33.64 \pm 2.20$ \\
& 3 & $33.75 \pm 2.40$ & $31.31 \pm 1.98$ \\
& 5 & $35.96 \pm 2.38$ & $32.76 \pm 1.59$ \\
& 7 & $37.66 \pm 1.75$ & $34.67 \pm 1.49$ \\
& 15 & $44.38 \pm 1.60$ & $44.12 \pm 1.7$ \\
& & \\
\hline
\end{tabular}

Values are means \pm standard deviations.

Group means within days did not differ significantly $(P>0.05)$.

\section{Face swelling:}

Post-operative edema was recorded in the study and control group and compared to each other as in (Tab.4). Significant decrease in edema was observed in the study group in comparing to control group from $1^{\text {st }}$ to 15 th post-operative days. Preoperatively, the mean of face thickness was $39.64 \pm 1.39 \mathrm{~mm}$ in the study group and $40.41 \pm 1.50 \mathrm{~mm}$ in control group. At the $1^{\text {st }}$ post-operative day, face edema was $43.81 \pm 1.85 \mathrm{~mm}$ which increased to $45.03 \pm$ $1.82 \mathrm{~mm}$ at $3^{\text {rd }}$ postoperative day, compared with $48.46 \pm 3.91 \& 49.54 \pm 3.95 \mathrm{~mm}$ in the control group respectively. Statistically there was significant difference between groups where $(\mathrm{P}<0.01)$.
At the $5^{\text {th }}$ postoperative day, the mean of face swelling was decreased to $43.49 \pm 2.06 \mathrm{~mm}$ in the study group and $46.80 \pm 3.45 \mathrm{~mm}$ in control group, with statistically significant difference between two groups $(\mathrm{P}<0.05)$.

At the seventh day, the swelling was $41.54 \pm$ $1.24 \mathrm{~mm}$ which was normally $(39.64 \pm 1.39 \mathrm{~mm})$ at 15 post-operative day.in the study group. In the control group, the swelling was $44.19 \pm 3.12$ which decrease to $39.57 \pm 1.39 \mathrm{~mm}$ without statistical significant difference between two groups, (Tab.4).

TAB. (4) Showing; Pero. \& Plowman of facial swelling, in mm, in both groups.

\begin{tabular}{|c|c|c|c|}
\hline \multicolumn{2}{|l|}{ Day } & Study group & Control group \\
\hline \multicolumn{2}{|l|}{ Preoperative } & $39.64 \pm 1.39$ & $40.41 \pm 1.50$ \\
\hline \multirow[t]{5}{*}{ Postoperative } & 1 & $43.81 \pm 1.85^{* *}$ & $48.46 \pm 3.91$ \\
\hline & 3 & $45.03 \pm 1.82 * *$ & $49.54 \pm 3.95$ \\
\hline & 5 & $43.49 \pm 2.06^{*}$ & $46.80 \pm 3.45$ \\
\hline & 7 & $41.54 \pm 1.24$ & $44.19 \pm 3.12$ \\
\hline & 15 & $39.64 \pm 1.39$ & $39.57 \pm 1.39$ \\
\hline
\end{tabular}

Values are means \pm standard deviations.

Group means within a day differ significantly $(* P<0.05 ; * * P<0.01)$.

\section{Thermal sensitivity}

Thermal Sensitivity of $2^{\text {nd }}$ molar was assessed and recorded pre- and postoperatively in both groups, in VAS of (0-10). Pre-operatively, there was no thermal sensitivity in all patients. Postoperatively, at $1^{\text {st }}$ and $3^{\text {rd }}$ day, the pain score was 2(2) in the study group in comparing to 4(4) and $5(5)$ in the control group respectively. At $5^{\text {th }}$ P.O. day, the pain score was more in the control group than in study group, where score (median) was 2(1) and 4(6) respectively, with highly significant differences $(\mathrm{P}<0.01)$. Only 2 patients complained of cold sensitivity at 7 and 15 P.O. days, where the pain score was 2(1) and 1(1) respectively, the pain was subsided with fluoride application after one month. In the control group, at $7 \& 15$ P.O. day, 
cold sensitivity was the main complaint in 6 patients, this sensitivity relieved in 4 patients after 2 months with fluoride application. Root canal filling was done in 2 patients of the control group due to continuity of sensitivity and pain severity. Statistical significant difference observed within groups $(\mathrm{P}<0.01)$ based on the non-parametric Mann Whitney test at each time point.

TAB. (5) Showing; Pre- and P.O thermal sensitivity score in both groups.

\begin{tabular}{|ll|l|l|}
\hline \multicolumn{1}{|l|}{ Day } & Study group & Control group \\
\hline Preoperative & & 0 & $0(0)$ \\
\hline Postoperative & 1 & $(2)^{*}$ & $4(4)$ \\
& 3 & $2(2)^{* *}$ & $5(5)$ \\
& 5 & $2(1)^{* *}$ & $4(6)$ \\
& 7 & $1(1)^{* *}$ & $4(4)$ \\
& 15 & $1(1)^{* *}$ & $2(3)$ \\
\hline
\end{tabular}

Values are medians (ranges).

Thermal sensitivity scores: 0 to 10 (refer to the methods section for explanation).

Groups within a day differ significantly $(* P<0.05$; $* * P<0.01)$

\section{Bone Density}

Bone density was measured at alveolar bone crest $\&$ middle of the socket (Region of interest
(ROI) in both groups. Measurement was taken immediately, 1,3 \& 6 months post-operatively and compared to each other in both groups. The mean of bone density in the study group, was $3991 \pm 113$ immediately which increased to $4813 \pm 361$ at 6 months postoperatively. In the control group, the mean of bone density was $3447 \pm 157$ which was increased to $4068 \pm 133$, but more decreasing than in the study group. Strong statistical significant difference observed within groups, where $(\mathrm{P}<0.01)$ (Tab.6).

TAB. (6) Showing immediate and P.O. mean of bone density at alveolar bone crest and middle of the socket in both groups.

\begin{tabular}{|c|l|l|}
\hline Postoperative (month) & Study group & Control group \\
\hline Immediate & $3991 \pm 113$ & $3447 \pm 157 * *$ \\
1 & $4133 \pm 123$ & $3504 \pm 153 * *$ \\
3 & $4397 \pm 183$ & $3773 \pm 157 * *$ \\
6 & $4813 \pm 361$ & $4068 \pm 133^{* *}$ \\
\hline
\end{tabular}

Values are means \pm standard deviations.

Group means within a day differ significantly $(* * P<0.01)$

Bone and overlying mucosal depression was observed in the control group, (Fig. 4) while good bone and preserved socket was observed clinically and radiographically in the study group (Fig.5).

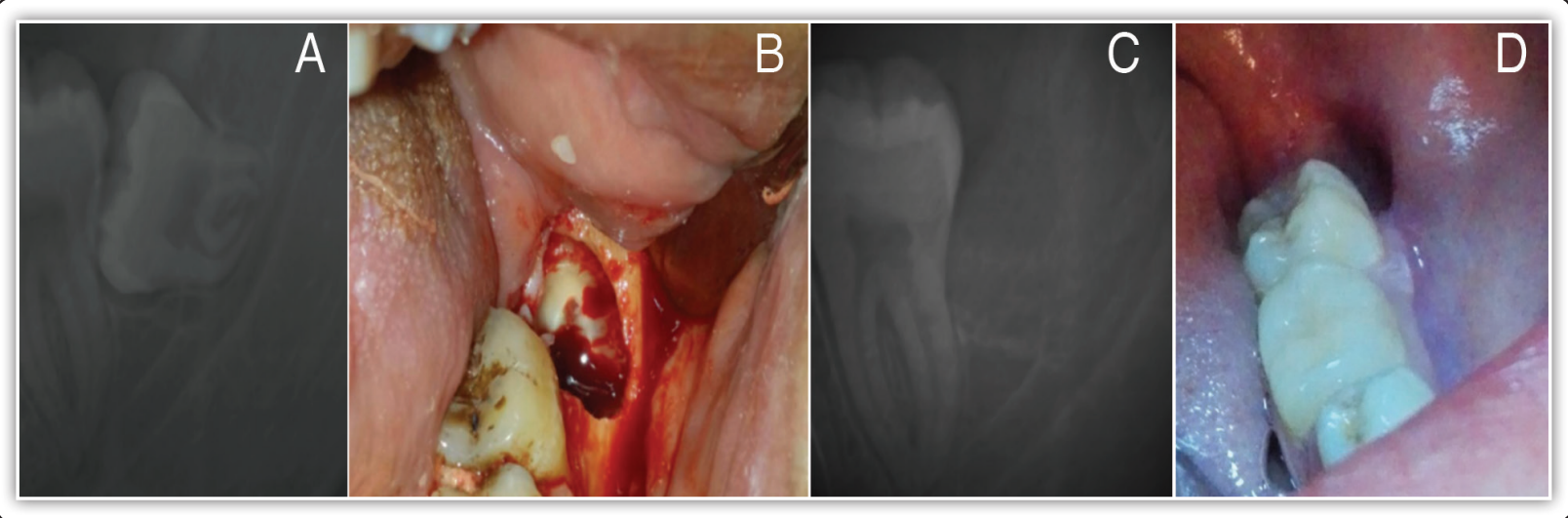

Fig. (4) Showing radiography(A), surgery(B) and follow-up post extraction in the control group. Deep bone depression with low bone density observed at $6 \mathrm{~m}$. (C\&D). 


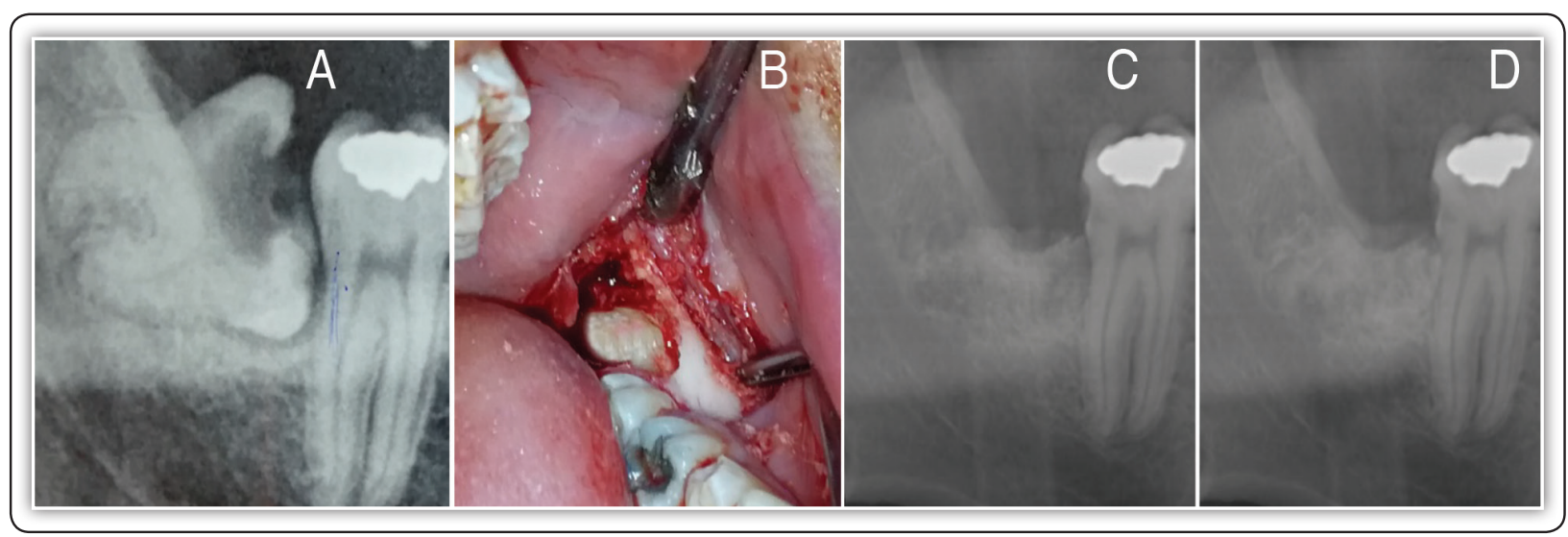

Fig. (5) Showing preoperative radiograph (A), application of MBM post-surgical extraction(B) and follow-up immediately (C) and at 6 months post extraction (D) in the study group.

\section{DISCUSSION}

Mineralized plasmatic matrix (MPM) was evaluated in the present study, following addition in the socket of extracted mandibular third molar. The patients age, sex and site of impaction was recorded and assayed, without statistical significant differences, $(\mathrm{P}>0.05)$. Minimum bleeding was encountered during the surgical procedure in both groups, as in agreement with Verselets ${ }^{(30)}$. This may be due to the care, handling and effect of the copious cooling with a physiological saline solution, which helped to good and clear working area.

The degree of surgical difficulty was evaluated based on anatomic factors (depth of impacted tooth and ramus relationship). Position of the third molar as assessed on radiographic examination and classification of Pell and Gregory ${ }^{(23)}$. In the present study, all the included mandibular third molars were of moderate difficulty (class II, level B). This condition was considered to reduce the risk factors and to obtain similarity between the 2 groups ${ }^{(31,32)}$.

This study compared the surgical outcomes of pain, swelling trismus, hypersensitivity, after extraction of mandibular third molars using MPM as a graft material. Regarding the postoperative pain, there was less pain score in MPM group as compared to the control group, from the $1^{\text {st }}$ to $7^{\text {th }}$ postoperative day. The pain in the control group was increased, reflected in increase number of analgesics taken by the patient. The result was statistically significant on the all days. This is contrary to kim et al. ${ }^{(33)}$ and Singh et al. ${ }^{(13)}$ who reported that the use of PRF had no effect on pain following the surgical removal of bilateral impacted mandibular third molars in a single appointment. This may be due to one side surgery and synthetic bone addition in the present study. In another search, patients treated with PRF had significantly less pain than those in the control group at $1^{\text {st }}$ postoperative day ${ }^{(34)}$. Autologous blood products rich in platelets and growth factors has stimulating action of growth factors and enhancing bone regeneration which is created by osteoconductive scaffolds. Several In vitro studies, animal experiments and clinical trials suggested that platelet concentrates may effectively trigger stimulation of osseous and soft tissue regeneration, and reduce inflammation, pain and unwanted side effects ${ }^{(35)}$.

From $1^{\text {st }}$ to 15 postoperative days, interincisal distance was used for the evaluation of trismus. Postoperative trismus evaluated in different studies, all of which measured the maximum mouth opening at specific time points. Trismus was significantly less in MPM group compared to the control group in whole period of this study. This may be due to 
antibacterial effect ${ }^{(18)}$ soft tissue regeneration, and reduced inflammation and unwanted side effects ${ }^{(36)}$. In addition to stimulating action of growth factors of plasmatic matrix ${ }^{(23)}$, however, statistical analysis did not indicate a significant difference in trismus between the MPM and control group on any time.

The most important postoperative complications were; pain, and swelling. Average duration of the intervention was the same in both groups. As regards the postoperative swelling, there was less swelling in the study group than in the control group from the $1^{\text {st }}$ to the $7^{\text {th }}$ postoperative day. This finding is in agreement with Robiony et al. ${ }^{(37)}$, who reported minimal postoperative swelling and pain when using plasmatic matrix. Various methods have been used to measure facial swelling with noninvasive, simple and time saving method, for determination of soft tissue contour changes ${ }^{(34)}$. Our study, in agreement with Kumar et al. ${ }^{(35)}$ reported statistical significant differences of swelling, between control and study group from $1^{\text {st }}$ to $5^{\text {th }}$ postoperative day.

Mineralized Plasmatic Matrix is a homogeneous product of mixing of two phases: the plasma phase and the mineral phase of bone graft that can be autogenic, allogeneic bone, or a bone substitute like xenogeneic bone synthetic. Fibrin network entraps platelets and leukocytes to release growth factors and no biochemical additives are needed ${ }^{(15,22)}$. The prospective cohort study conducted by Barone et al. ${ }^{(38)}$ in treating full or partial buccal bone defects of fresh extraction sockets in the esthetic zone showed that the effect of graft and PRF in repairing bone defects before implant placement. Moreover, the grafted sockets did not compromise bone formation. Synthetic bone graft with PRF was used in the present study, so that the bone preserved at the site of extraction and adjacent to second molar which leading to decrease thermal sensitivity and enhance bone formation.

MPM is natural and autogenous product that can enhance stability to the bone particles. Platelets also play a role in host defense mechanisms at the wound site, which attract macrophage cells. Platelet concentrates may contain small amounts of leukocytes that synthesize interleukins involved in the non-specific immune reaction ${ }^{(39)}$. Antimicrobial activity of platelet concentrates against several bacterial species involved in oral infections has also been reported ${ }^{(18)}$. So that, in the present study, the soft tissue wound healed without complication, the pain, swelling and trismus decreased in whole time of evaluation more than in the control group. Slow release of growth factors and matrix glycoproteins to enhancing bone graft during 7 days in MPM in addition to significant bone regeneration and maturation with increasing bone density ${ }^{(39)}$. In the present study, the density was increased with MPM more than control group.

Also, Post-extraction alveolar bone changes have been estimated to cause $50 \%$ reduction in the buccolingual width of alveolar bone ${ }^{(39)}$. Systematic review evaluated the dimensional changes of the alveolar ridge following tooth extraction and showed a mean reduction of $3.8 \mathrm{~mm}$ in width and $1.24 \mathrm{~mm}$ in height in the first six months ${ }^{(6)}$. The predictable bone resorption is occur with the buccal aspect resorbing first ${ }^{(23)}$. Insufficient bone may compromise lower second molar with a risk of root expose and injuring the anatomical structures. Therefore, adequate alveolar ridge preservation is essential ${ }^{(40)}$. In the present study, cold sensitivity not observed in MPM in contrary to control group. So that alveolar socket preservation, techniques include the use of grafting materials of human, animal or synthetic origin, with or without the use of barrier membranes should be indicted particularly in surgical extract of deep impaction $^{(41)}$.

\section{REFERENCES}

1. De Santana-Santos T, De Souza-Santos JA, Martins-Filho PR, Da Silva LC, De Oliveira E, Silva ED, et al. Prediction of postoperative facial swelling, pain and trismus following third molar surgery based on preoperative variables. Med Oral Pathol Oral Cir Bucal 2013; 18: 65-70. 
2. Yuasa H, Sugiura M. Clinical postoperative findings after removal of impacted mandibular third molars: Prediction of postoperative facial swelling and pain based on preoperative variables. Br J Oral Maxillofac Surg 2004; 42: 209-14.

3. Monaco G, Cecchini S, Gatto MR, Pelliccioni GA. Delayed onset infections after lower third molar germectomy could be related to the space distal to the second molar. Int. J. Oral Maxillofac Surg 2016; 3509: 1-6.

4. Clauser B, Barone R, Briccoli L. Complications in surgical removal of mandibular third molars. Minerva Stomatol 2009; 58:359-64.

5. Goldberg MH, Nemarich AN, Marco WP. Complications after mandibular third molar surgery: a statistical analysis of 500 consecutive procedures in private practice. $\mathrm{J}$ Am Dent Assoc 1985; 111: 277-9.

6. Tan WL, Wong TL, Wong MC, Lang NP. A systematic review of post-extraction alveolar hard and soft tissue dimensional changes in humans. Clinical Oral Implants Research 2012; 5:1-21.

7. Kugelberg CF, Ahlström U, Ericson S, Hugoson A, Kvint S. Periodontal healing after impacted lower third molar surgery in adolescents and adults. A prospective study. Int J Oral Maxillofac Surg 1991; 20:18-24.

8. Oltramari PV, Navarro Rde L, Henriques JF, Taga R, Cestari TM, Janson G. Evaluation of bone height and bone density after tooth extraction: An experimental study in minipigs.Oral Surg Oral Med Oral Pathol Oral Radiol En$\operatorname{dod} 2007 ; 104: 9-16$.

9. Nathani DB, Sequeira J, Rao B. Comparison of platelet rich plasma and synthetic graft material for bone regeneration after third molar extraction. Ann Maxillofac Surg 2015; 5: 213-18.

10. Choukroun J, Diss A, Simonpieri A, Girard MO, Schoeffler C, Dohan SL, et al. Platelet-rich fibrin (PRF): A second-generation platelet concentrate. Part IV: Clinical effects on tissue healing. Oral Surg Oral Med Oral Pathol Oral Radiol Endod. 2006; 101: 56-60.

11. Oncu E, Bayram B, Kantarci A, Gulsever S, Alaaddinoglu EE. Positive effect of platelet rich fibrin on osseointegration. Med Oral Pathol Oral Cir Bucal. 2016; 21(5):601-07.

12. Bielecki TM, Gazdzik TS, Arendt J,Szczepanski T, Krol W, Wielkoszynski T. Antibacterial effect of autologous platelet gel enriched with growth factors and other active substances: anin vitro study. J Bone Joint Surg Br. 2007; 89: 417-420
13. Singh A, Kohli M, Gupta N. Platelet rich fibrin: a novel approach for osseous regeneration. J Maxillofac Oral Surg. 2012;11(4):430-4.

14. Dohan Ehrenfest DM, de Peppo GM, Doglioli P, Sammartino G. Slow release of growth factors and thrombospondin-1 in Choukroun's platelet-rich fibrin (PRF): a gold standard to achieve for all surgical platelet concentrates technologies. Growth Factors. 2009; 27(1): 63-6

15. Geurs N, Ntounis A, Vassilopoulos P, Van der Velden $\mathrm{U}$, Loos BG, Reddy M. Using growth factors in human extraction sockets: a histologic and histomorphometric evaluation of short-term healing. Int J Oral Maxillofac Implants 2014; 29: 485-96.

16. Perisse J. Du PRF et PRP vers les Matrices Plasmatiques Mineralizes (MPM) in implantologie. Rev d' Implant. 2011; 29: 63-69.

17. EL-Moheb M, Al-Zarea B, Sghaireen M, Toriya J, Mizohata A, Patil S, et al. Mineralized Plasmatic Matrix to Enhance the Bone Grafting Technique. J Hard Tiss Biol 2017; 26: 289-92.

18. Nadon F, Chaput B, Perisse J, De Berail A, Lauwers F, Lopez R. Interest of mineralized plasmatic matrix in secondary autogenous bone graft for the treatment of alveolar clefts. J Craniofac Surg 2015; 26: 2148-51.

19. Ruga E, Gallesio C, Boffano P. Platelet-rich fibrin and piezoelectric surgery: a safe technique for prevention of periodontal complications in third molar surgery. J Craniofac Surg. 2011; 22: 1951-55.

20. Marx RE, Carlson E, Eichstaedt RM, Schimmele SR, Strauss JE, Georgeff KR. Platelet-rich plasma: growth factor enhancement for bone grafts. Oral Surg Oral Med Oral Path Oral Rad Endodon 1998; 85: 638-46.

21. Horváth A, Mardas N, Mezzomo LA, Needleman IG, Donos N. Alveolar ridge preservation. A systematic review. Clin Oral Investig 2013;17(2): 341-63

22. Samir E, Hicham S, Keltoum EO, Zouheir I. Management of post-extractional alveolar socket with mineralized plasmatic matrix before implant placement: A case report. Asian Pac. J. Health Sci 2017; 4: 220-27.

23. Pell GJ, Gregory BT. Impacted mandibular third molars: classification and modified techniques for removal. Dent Dig 1933; 39: 330-8 
24. Fabbro M, Bortolin M, Taschieri S. Is autologous platelet concentrate beneficial for post-extraction socket healing? A systematic review. Int J Oral Maxillofac Surg 2011; 40: $891-900$

25. Oikarinen K. Postoperative pain after mandibular thirdmolar surgery. Acta Odontol Scand 1991; 49:7-13.

26. Scott J, Huskisson EC: Graphic representation of pain. Pain 2:175, 1976

27. Ustun Y,Erdoğan Ö, Esen E, Karsli ED. Comparison of the effects of 2 doses of methylprednisolone on pain, swelling, and trismus after third molar surgery. Oral Surg Oral Med Oral Pathol Oral Radiol Endod. 2003; 96:535-39.

28. Peretz B, Kaffe I, Amir E. Digital images obtained with a digital camera are not associated with a loss of critical information. A preliminary study. Br Dent J 2009; 206: 9-18.

29. Goes P, Lima AP, Melo IM, Rego RO, Lima V. Effect of atorvastatin in radiographic density on alveolar bone loss in wister rats. Braz Dent J 2010; 21:193-98.

30. Vercellotti T: Technological characteristics and clinical indications of piezoelectric bone surgery. Minerva Stomatol 2004; 53:207-12.

31. .Schropp L, Wenzel A, Kostopoulos L, Karring T. Bone healing and soft tissue contour changes following single tooth extraction: a clinical and radiographic 12-month prospective study. International Journal of Periodontics \& Restorative Dentistry 2003; 23(4):313-23

32. Oikarinen K. Postoperative pain after mandibular thirdmolar surgery. Acta Odontol Scand 1991;49:7-13.

33. Kim JH, Lee DW, Ryu DM. Effect of platelet-rich fibrin on pain and swelling after surgical extraction of third molars. J Tissue Eng Regen Med. 2011; 8:80-6.
34. David DM, Dohan E, Corso M, Diss A, Mouhyi J, Charrier J. Three-Dimensional Architecture and Cell Composition of a Choukroun's Platelet-Rich Fibrin Clot and Membrane. Periodontol 2010; 81:546-55.

35. Kumar N, Prasad K, Lalitha RM, Ramanujam L, K R, Dexith J, Chauhan A. Evaluation of treatment outcome after impacted mandibular third molar surgery with the use of autologous platelet rich fibrin: a randomized controlled clinical study. J Oral Maxillofac Surg. 2014; 11: 1-13.

36. Anitua E, Andia I, Ardanza B, NurdenP, Nurden AT. Autologous platelets as a source of proteins for healing and tissue regeneration. ThrombHaemost2004: 91: 4-15.

37. Robiony M, Pollni F, Costa F, Vercelloti T, Politi M. Piezoelectric bone cutting in Multipiece Maxillary Osteotomies. J Oral Mxillofac Surg 2004; 62:759-61.

38. Barone A, Ricci M, Romanos GE, Tonelli P, Alfonsi F, Covani U. Buccal bone deficiency in fresh extraction sockets: a prospective single cohort study. Clin Oral Implants Res. 2015; 26: 823-30.

39. Marx RE, Carlson ER, Eichstaedt RM, Schimmele SR, Strauss JE, Georgeff KR. Platelet-rich plasma: growth factor enhancement for bone grafts. Oral Surg Oral Med Oral Pathol Oral Radiol Endod 1998: 85: 638-646.

40. Tan WL, Wong TL, Wong MC, Lang NP. A systematic review of post-extraction alveolar hard and soft tissue dimensional changes in humans. Clinical Oral Implants Research 2012; 23Suppl 5:1-21

41. Chignon Sicard B, Georgiou CA, Fontas E, David S, Dumas P, Ihrai T, et al. Efficacy of leukocyte- and plateletrich fibrin in wound healing: a randomized controlled clinical trial. Plast Reconstr Surg 2012; 130:819-29. 
